\title{
A Systematic Review of Recent Research on Adolescent Social Connectedness and Mental Health with Internet Technology Use
}

\author{
Yi-Ju Wu ${ }^{1}$ (i) $\cdot$ Corliss Outley $^{1} \cdot$ David Matarrita-Cascante ${ }^{1} \cdot$ Theresa Pesl Murphrey $^{2}$
}

Received: 12 June 2015/Accepted: 24 July 2015/Published online: 2 August 2015

(C) Springer International Publishing 2015

\begin{abstract}
An increase in the use of online technology among adolescents has influenced their sense of connectedness in various ways. Some studies suggest that there are positive aspects of online technology, especially in providing opportunities for youth to develop and maintain a sense of connectedness in an online environment, while other studies suggest that young people's use of online technology creates the opposite and leads to feelings of loneliness, depression and social anxiety, and creates mental health challenges among adolescents. Although a substantial number of studies suggests that young people stay in the digital landscape for social activities, there have been few studies that have addressed its effects on feelings of connectedness and mental health. This study reports the findings of a systematic review of recent research addressing the associations between adolescents' sense of social connectedness and Internet technology use. Adolescents are becoming accustomed to technology and remaining in the virtual playground in part to experience the positive reinforcement of social connections. Although Internet technology might provide additional opportunities for adolescents to seek emotional connection with friends and school, this study suggests that real-life social skills are still a necessary foundation for them to use technology in a beneficial way. Taken collectively, the articles reviewed suggest that adults who interact with youth should incorporate Internet technology
\end{abstract}

Yi-Ju Wu

yiju_wu@tamu.edu

1 Department of Recreation, Park and Tourism Sciences, Texas A\&M University, R 121 AGLS, College Station, TX 77843-2261, USA

2 Department of Agricultural Leadership, Education, and Communications, Texas A\&M University, College Station, TX, USA into their work, and consider the development of a digital landscape to promote adolescents' social connectedness.

Keywords Social connectedness - Adolescent - Internet technology use $\cdot$ Mental health

\section{Introduction}

Social connectedness plays an essential role in the everyday lives of adolescents and is a key to positive personal development, lifestyle, and general health (Barber and Schluterman 2008; Stoddard et al. 2011; Uchino et al. 1996). Researchers have found that a higher level of social connectedness among adolescents not only contributes as a protective factor against an array of risk behaviors but also fosters more positive mental health outcomes by decreasing feelings of anxiety, depression, and loneliness (Beam et al. 2002; DuBois and Silverthorn 2005; Hawkins et al. 1999; Zimmerman et al. 2002). Further, the degree of connectedness to the different social domains (i.e., family, school, friends and community) in adolescence is not only a factor for their positive development, lifestyle, and general health behaviors, but also a predictor of their sense of well-being in adulthood (Olsson et al. 2013). Walton and Cohen (2011) argue that an adolescent's sense of social connectedness is generated by a process that seeks to create a social linkage to their social world - a world that includes self-identity formation, feelings of belonging, personal interests and motivated behaviors. Adolescents actively seek this sense of connectedness; if support is received to achieve this connectedness, the connectedness itself can positively contribute to their mental health and likely positively affect their future behaviors.

An increase in the use of Internet technology among adolescents has influenced their behaviors to seek a sense 
of connectedness in various ways. The ecological environment for the digital generation has shifted from a focus on only physical surroundings to a digital landscape where adolescents spend their time within virtual playgrounds on a regular basis. The Pew Research Center (2013) reported that $93 \%$ of young people use the Internet at least occasionally. A national survey reported that $95 \%$ of all teenagers ages 12-17 years are online in the United States (Madden et al. 2013). This suggests that adolescents are becoming increasingly well-versed in technology and the digital landscape, where virtual playgrounds are part of the social environment and a common destination for adolescents. Bers (2012) proposed that one of the features of technology is the creation of a digital landscape playground where adolescents are able to construct a sense of connection. Thus, Internet technology can be viewed as a potentially effortless, integrated, and automated way to provide a space in a digital landscape for adolescents to construct their social connectedness.

Although a substantial number of studies suggest that young people engage in the digital landscape for social activities, there have been few studies that have addressed, in a systematic way, the effects of adolescents' Internet technology use on their sense of connectedness. Some research suggests that there are positive aspects of Internet technology, especially in providing opportunities for individuals to develop and maintain a sense of connectedness in an online environment (Grieve et al. 2013). Boyd (2008) argues that Internet technology provides adolescents a space to explore identity formation, negotiate status, and socially engage with their peers. On the other hand, other researchers argue that young people's use of Internet technology leads to the opposite of feelings of connection, resulting in depression, anxiety, and loneliness that can create mental health challenges among adolescents (Irvine 2009; Pierce 2009). The literature is not clear regarding the implications of using technology among adolescents. Therefore, we set to examine the relationship that exists between these factors (i.e., use of Internet technology and connectedness and use of Internet technology and mental health) by answering the overall research questions: What is the relationship between adolescents' Internet technology use and their sense of connectedness? and What is the relationship between adolescents' online Internet technology and their levels of depression, anxiety, and loneliness? We do this by engaging in a systematic review of the existing body of literature as described below.

\section{Internet Technology}

People use Internet technology for various purposes including seeking information, entertainment, commerce, communication, and creating new relationships (Sum et al. 2008). The notion of "Internet technology" was originally derived from the concept of information technology. Information technology refers to the distribution of information using delivery technologies such as television, telephones, and computers. Internet technology expands on the concept of information distribution by incorporating the exchange of information into its definition. Mistler-Jackson and Songer (2000) argue that the initial use of Internet technology was designed to permit communication through interaction with one another instead of simply transmitting information. The term "Internet technology" refers to the utilization of electronic devices for interpersonal interactions and communications (Mistler-Jackson and Songer 2000). Bringing these perspectives together, Internet technology use among adolescents as used in this review refers to the utilization of electronic devices connected to the Internet for interpersonal relations, interactions and communications within their ecological environment in their daily life (Mistler-Jackson and Songer 2000). The increased use of Internet technologies has created new capabilities for communication and interaction with adolescents' ecological environment, which in turn has led many adolescents to spend a significant amount of time online interacting with friends (Mistler-Jackson and Songer 2000; Sum et al. 2008).

\section{Conceptualization of Social Connectedness and Mental Health}

Social connectedness is a critical aspect of human life, particularly critical in the formative years. Social connectedness becomes a major mechanism by which adolescents learn how to interact with their social environment, as well as with their sense of self. Understanding the ways in which adolescents spend their daily lives is important, particularly as it relates to their sense of connectedness within their social environment. Researchers have found that a higher level of social connectedness among adolescents not only constitutes a potential protective factor against an array of risk behaviors, but also fosters improved mental health outcomes by decreasing feelings of anxiety, depression, and loneliness (Beam et al. 2002; DuBois and Silverthorn 2005; Hawkins et al. 1999; Zimmerman et al. 2002). The definition of adolescent social connectedness as used in this review refers to the positive bonds, interactions and relationships with people, places, and things in an adolescent's ecological environment (Karcher 2011).

Improvements in mental health achieved through enhanced social connectedness should be expected to reflect positive bonds, interactions and relationships with people, places, and things in an adolescent's ecological 
environment, and result in lower levels of depression, anxiety and loneliness. The feelings of depression, anxiety, and loneliness among adolescents are significantly decreased upon individuals' higher levels of social connectedness (Beam et al. 2002; DuBois and Silverthorn 2005; Hawkins et al. 1999; Zimmerman et al. 2002). These mental health problems are postulated to be improved through enhanced social connectedness. Three specific mental health challenges thought to be improved by enhanced social connectedness-depression, anxiety and loneliness-were also targeted in selecting research to be reviewed.

\section{The Current Study}

A relatively small number of studies have been produced in the themes explored here. This is an indicator of breadth of the literature surrounding youth Internet technology use, the development of social connectedness, and the mental health circumstances of such adolescents. Given the increase in Internet use by adolescents and the increase in mental health challenges facing youth populations, this area of research holds importance.

This review reports the findings of a systematic review of recent research examining the associations between adolescents' Internet technology use and their social connectedness, as well as their levels of depression, anxiety and loneliness.

\section{Methods}

We engaged in a systematic review of the literature focused on Internet technology usage among adolescents and specific implications of adolescents' sense of connectedness and their levels of depression, anxiety, and loneliness. To avoid possible selection bias, criteria for this systematic review were developed with the intent of locating all directly relevant articles.

\section{Database Search}

The data for this review consisted of articles from the following five online databases: CINAHL, ERIC, Psychology and Behavioral Sciences Collection, Science and Technology Collection and the refined EBSCO Social Sciences database. The initial search was narrowly construed in conceptual and logical terms: (adolescent OR adolescence $)+($ social connectedness OR sense of connectedness) + (depression OR anxiety OR loneliness $)+($ Internet technology). This search returned no articles.
However, the use of a more broadly-construed search included the following keywords: (teenager OR young people OR youth OR adolescents OR adolescence + (online technology OR Internet technology OR social media OR social network OR social networking) + (social connectedness OR connectedness OR connection or connect OR relationship OR relationships OR friendship) + (mental health OR depression OR anxiety OR loneliness). This second search resulted in the identification of 268 articles.

The resulting group of 268 articles was defined as the initial pool. The need for an additional, more broadlyconstrued, iteration illustrates an interesting characteristic of this literature: the rubric used by scholars doing work relevant to this theme is far from standardized.

\section{Inclusion and Exclusion Criteria}

The 268 articles retrieved in the initial search were then filtered through three specific inclusion/exclusion criteria. Articles were excluded if they were (1) not published in English, (2) not published in an academic journal and (3) not published after 1980. A total of 32 articles were excluded in this selection step. Two were excluded because of publication date and 30 appeared in non-academic outlets. After this first screening, 236 articles remained for further review.

The second screening involved sifting the abstracts of the remaining 236 articles so as to narrow the study to research (1) most directly relevant to the selected substantive focus, and (2) that used systematic methods that would permit robust inferences. To accomplish this, four additional inclusion criteria were applied: (1) an unambiguous focus on adolescents, (2) the use of experimental or observational research designs in the studies reviewed, (3) an explicit focus on social connectedness and its potential impacts on depression, anxiety and/or loneliness, and (4) the treatment of Internet technology use as a causal factor, or prospective intervention. If it was not clear from the abstract whether the criteria were met, the article was included in the final screening process. The inclusion and exclusion criteria used for this systematic review are provided below (see Table 1).

A total of 220 articles were excluded in the second round. Nineteen articles were excluded because they did not focus specifically on adolescents (e.g., they dealt with young adults, college students), or did not have at least experimental and observational research design (e.g., meta-analysis). A total of 101 articles were excluded because the outcomes treated in the articles were not the three mental issues we are focusing on (e.g., they dealt with adjustment, suicide, wellbeing, or other mental health issues). One hundred articles were excluded because Internet technology 
Table 1 Sample inclusion and exclusion criteria

\begin{tabular}{|c|c|c|}
\hline Criteria & Inclusion & Exclusion \\
\hline Intervention & $\begin{array}{l}\text { Internet use, social media, social network, instant messaging and } \\
\text { email }\end{array}$ & $\begin{array}{l}\text { Phone text, video, game play, Internet addiction and online } \\
\text { entertainment }\end{array}$ \\
\hline Outcomes & $\begin{array}{l}\text { Social connectedness, connectedness, friendship, relationship, } \\
\text { mental health issues for depression, anxiety, loneness, social } \\
\text { isolation }\end{array}$ & $\begin{array}{l}\text { Bullying, attitude, health behavior, satisfaction, personality, } \\
\text { self-perception, adaptability, self-efficacy, resilience, } \\
\text { cognition, suicide }\end{array}$ \\
\hline Methodology & $\begin{array}{l}\text { Experimental and observational research that seeks to investigate } \\
\text { Internet technology on adolescent social connectedness and } \\
\text { mental health }\end{array}$ & $\begin{array}{l}\text { Literature review, meta-analysis, non-peer reviewed } \\
\text { literature, expert opinion and magazines }\end{array}$ \\
\hline Sampling & Adolescence or teenagers or youth or young people & Young adult, college student, adult, elder, child \\
\hline Language & English & Not English \\
\hline Sources & Academic journal & Magazine, Dissertation, Reviews and Reports \\
\hline $\begin{array}{l}\text { Published } \\
\text { date }\end{array}$ & Studies from 1980 to current & Studies before 1980 \\
\hline
\end{tabular}

use was not treated as an intervention or prospective causal factor in the study. After this second screening, 16 articles remained for further review.

For the third round screening process, the same inclusion criteria from the second screening were applied, but now to the full text of each article. After full text screening of the 16 articles, four were excluded on the basis of the intervention or age group criterion, resulting in a final sample size of $n=12$.

\section{The Three-Tier Screening Process}

The inclusion/exclusion procedures listed above served as the first round of screening in the three-tier process. For the screening process, the PRISMA flow chart developed by Liberati et al. (2009) was used to determine eligible articles to be included in the final analysis. The flowchart in Fig. 1 depicts the number of articles identified during the systematic review and indicates the number of included and excluded articles.

A total of 12 studies satisfied the above criteria for inclusion in the review (see Table 2 for summary).

\section{Results}

\section{Sample Characteristics and Locations}

The smallest sample size studied in the included articles was $\mathrm{n}=15$ and the largest, $\mathrm{n}=1684$. The subjects included early adolescents (from 11 years) to late adolescents (21 years). Two of the twelve studies had male-only samples and/or were recruited from non-school settings (Delonga et al. 2011; Lim et al. 2013). The remaining ten studies involved mixed-gender samples and recruitment was from schools. The participants in one study had physical disabilities, and the subjects in the other study were identified as bisexual. For both of these groups, the research indicated that cyberspace could be a consequential setting for adolescents with special backgrounds. Three studies were conducted each in the United States and Australia, and one study was conducted in each of six countries-Finland, Taiwan, Korea, Serbia, Belgium and Singapore. The collective breadth of these studies permits drawing defensible inferences about some of the characteristics of the growing trend among adolescents regarding use of Internet technology.

Seven of the twelve studies indicated that an adolescent's cyber-relationship is an extension of offline connections and potentially correspond to a real life relationship (Dempsey et al. 2009; Donchi and Moore 2004; Gross et al. 2002; Huang and Yang 2013; Lim et al. 2013; Punamäkia et al. 2009; Raghavendra et al. 2012). Cyberspace becomes a supportive opportunity for the extension connections that increases connections with friends and peers (Lim et al. 2013; Raghavendra et al. 2012). In other words, the negative peer interactions (i.e., cyberbullying) may be difficult to cut-off with the extension cyber-relationships (Dempsey et al. 2009). Also, adolescents who tend to portray oneself as loveable online fail to achieve success in cyber-relationship when they have poor social skills and the lack of social confidence in the real worlds (Donchi and Moore 2004; Gross et al. 2002; Huang and Yang 2013; Punamäkia et al. 2009).

Perhaps, not surprisingly, the outlets in which the respective studies were published conform to the characteristics of the sample of subjects. For example, Raghavendra et al. (2012) conducted a study on participants with physical disabilities and published the research 


\begin{tabular}{|c|c|}
\hline $\begin{array}{l}0 \text { articles identified through the } \\
\text { database search with } 4 \text { subject term } \\
\text { (adolescent OR adolescence, social connectedness } \\
\text { OR sense of connectedness, depression OR anxiety } \\
\text { OR loneliness and Internet technology) } \quad \mathrm{n}=0\end{array}$ & $\begin{array}{l}\text { Redefine keywords for searching: } \\
\text { 1) teenager OR young people OR youth OR adolescents OR } \\
\text { adolescence; 2) online technology OR Internet technology } \\
\text { OR Social media OR social network OR social networking; } \\
\text { 3) social connectedness OR connectedness OR connection or } \\
\text { connect OR relationship OR relationships OR friendship; } \\
\text { and 4) mental health OR depression OR anxiety OR } \\
\text { loneliness. }\end{array}$ \\
\hline $\begin{array}{l}268 \text { articles identified through the } \\
\text { database search with redefined } \\
\text { keyword } \\
\qquad \mathrm{n}=268\end{array}$ & $\begin{array}{l}32 \text { articles excluded because of published date }(n=2) \\
\text { and sources }(n=30) \text { criteria } \\
236 \text { after first round }\end{array}$ \\
\hline $\begin{array}{l}236 \text { articles remain to read in order to } \\
\text { determine inclusion. } \\
\qquad \mathrm{n}=236\end{array}$ & $\begin{array}{l}220 \text { articles excluded because of sampling and research } \\
\text { design }(n=19), \text { outcomes }(n=101) \text { and intervention } \\
(n=100) \text { criteria } \\
16 \text { after second round }\end{array}$ \\
\hline $\begin{array}{l}16 \text { articles read in order to determine } \\
\text { inclusion. } \\
\qquad n=16\end{array}$ & $\begin{array}{l}4 \text { articles excluded after reading the full article. } \\
12 \text { after third round }\end{array}$ \\
\hline $\begin{array}{l}12 \text { articles met the inclusionary } \\
\text { criteria. } \\
\qquad n=12\end{array}$ & $\begin{array}{l}12 \text { articles excluded after reading the full article. } \\
2 \text { qualitative studies } \\
10 \text { quantitative studies }\end{array}$ \\
\hline
\end{tabular}

Fig. 1 Flow of articles through the systematic review

Table 2 Summary of study articles

\begin{tabular}{lllllll}
\hline References & $\mathrm{n}$ & Age & Gender & Recruit & Location & Type of study (Methodology) \\
\hline Banjanin et al. (2015) & $\mathrm{n}=336$ & Mean age 18 & Mixed & School & Serbia & Quantitative (Survey) \\
Frison and Eggermont (2015) & $\mathrm{n}=910$ & Mean age 15 & Mixed & School & $96 \%$ Belgium & Quantitative (Survey) \\
Huang and Yang (2013) & $\mathrm{n}=608$ & $13-18$ & Mixed & School & Taiwan & Quantitative (Survey) \\
Lim et al. (2013) & $\mathrm{n}=36$ & $13-18$ & Male only & Counseling center & Singapore & Qualitative (Interview) \\
Park et al. (2012) & $\mathrm{n}=795$ & $12-13$ & Mixed & School & Korea & Quantitative (Survey) \\
& & $15-16$ & & & Australia & Qualitative (Interview) \\
Raghavendra et al. (2012) & $\mathrm{n}=15$ & $11-18$ & Mixed & School & USA & Quantitative (Survey) \\
Delonga et al. (2011) & $\mathrm{n}=49$ & $14-19$ & Male only & Youth program & Australia & Quantitative (Survey) \\
Holtz and Appel (2011) & $\mathrm{n}=205$ & $10-14$ & Mixed & School & USA & Quantitative (Survey) \\
Dempsey et al. (2009) & $\mathrm{n}=1684$ & $11-16$ & Mixed & School & Finland & Quantitative (Survey) \\
Punamäkia et al. (2009) & $\mathrm{n}=478$ & $10-13$ & Mixed & School & Australia & Quantitative (Survey) \\
Donchi and Moore (2004) & $\mathrm{n}=336$ & $15-21$ & Mixed & School & USA & Quantitative (Survey) \\
Gross et al. (2002) & $\mathrm{n}=130$ & $11-13$ & Mixed & School & &
\end{tabular}

in Technology and Disability. Delonga et al. (2011) recruited a sample from a Lesbian, Gay, Bisexual, and Transgender (LGBT) community center, and the study was published in Sexual Addiction and Compulsivity.

\section{Study Design and Publishing}

Study designs for the articles included both qualitative and quantitative approaches. Two of the 12 articles-the two 
referred to directly above-utilized qualitative approaches. Ten articles were quantitative studies that utilized crosssectional surveys. Specifically, one study collected mixedmethod data and included a combination of survey responses and daily personal reports (Gross et al. 2002). The daily report was considered supplemental to the survey responses.

Four of the 12 studies came from sources specialized in computer use. One was focused on computer use in education and published in Journal of Educational Computing (Huang and Yang 2013); three dealt more broadly with the impact of computer use on human behavior were published in Computers in Human Behavior (Banjanin et al. 2015; Frison and Eggermont 2015; Lim et al. 2013); and one publication was in the field of disability studies and published in Technology and Disability (Raghavendra et al. 2012).

The outlets for other seven studies were carried out within the scope of adolescent development included Australian \& New Zealand Journal of Psychiatry (Park et al. 2012), Behaviour Change (Donchi and Moore 2004), Internal Journal of Behavioral Development (Punamäkia et al. 2009), the Journal of Adolescence (Holtz and Appel 2011), the Journal of Social Issues (Gross et al. 2002), Psychology in the Schools (Dempsey et al. 2009), and. Sexual Addiction and Compulsivity (Delonga et al. 2011)

\section{Study Content Focus}

Each of the articles reviewed yielded findings relevant to Internet technology use and its relationship to adolescents' social connectedness and mental health regarding levels of depression, anxiety and loneliness. Six articles illustrated the influence of Internet technology use in adolescent social connectedness (Donchi and Moore 2004; Gross et al. 2002; Holtz and Appel 2011; Lim et al. 2013; Punamäkia et al. 2009; Raghavendra et al. 2012). A total of 10 out of 12 studies examined the influence that Internet technology has on the mental health of adolescents (Banjanin et al. 2015; Delonga et al. 2011; Dempsey et al. 2009; Donchi and Moore 2004; Frison and Eggermont 2015; Gross et al. 2002; Holtz and Appel 2011; Huang and Yang 2013; Punamäkia et al. 2009). Below is a summary to describe the findings of articles and yield the results of this review (see Table 3).

The relationships between adolescents' Internet technology use and their connectedness to friends, school and family were determined through the findings of reviewing articles. The two studies that focused on school connectedness found that this connectedness was improved by Internet technology use (Gross et al. 2002; Raghavendra et al. 2012). According to these studies, young people use the Internet to seek out additional opportunities to interact with school-based peers. Four of the five studies contended that Internet technology use promotes connectedness among friends (Donchi and Moore 2004; Gross et al. 2002; Lim et al. 2013; Raghavendra et al. 2012). The exception was the study completed by Punamäkia et al. (2009), in which the use of Internet technology was said to lead adolescents toward poor peer relationships. However, young people rarely used the Internet to communicate with their family members. Specifically, two of three studies indicated no association between adolescents' Internet technology use and the sense of family connections (Holtz and Appel 2011; Raghavendra et al. 2012) and one concluded adolescents' Internet technology use leads to weak relationships with parents (Punamäkia et al. 2009). Interestingly, researchers often used the term "cyber-relationship" to define an adolescent's connection and interactions with Internet technology, and suggest that adolescents consciously seek to manage their relationship with the Internet (Gross et al. 2002; Huang and Yang 2013). Overall, the review of these articles leads to the conclusion that Internet technology use is associated with friends and school connectedness but not family connectedness.

The review also focused on literature that sought to link adolescents' Internet technology use to mental health problems including levels of depression, anxiety and loneliness. Regarding the levels of depression, four of the five studies concluded that there is no association between the use of Internet technology and feelings of depression (Banjanin et al. 2015; Dempsey et al. 2009; Frison and Eggermont 2015; Holtz and Appel 2011), and only one of five studies found a relationship between these two variables (Park et al. 2012). Two of three studies concluded the greater the Internet technology use, the higher the level of anxiety (Delonga et al. 2011; Gross et al. 2002); one study determined that there was no association (Holtz and Appel 2011) between Internet technology use and social anxiety. Five of six studies found the greater the Internet technology use, the higher the level of loneliness (Delonga et al. 2011; Donchi and Moore 2004; Gross et al. 2002; Huang and Yang 2013; Punamäkia et al. 2009), but one showed no association (Holtz and Appel 2011). Overall, these articles do not support the notion that Internet technology contributes positively to an adolescent's mental health by lowering levels of depression, anxiety or loneliness.

\section{Discussion}

This study sought to clarify confusion related to Internet technology use and adolescent social connectedness revealed in the literature through an in-depth systematic article review addressing the influence of adolescents' Internet technology use on their social connectedness and association with varying mental health issues. The review 
Table 3 Summary of results by domain focus

\begin{tabular}{|c|c|c|c|c|}
\hline Subject & Domain & $\begin{array}{l}\text { \# of } \\
\text { Studies }\end{array}$ & Results & References \\
\hline \multirow{6}{*}{$\begin{array}{l}\text { Internet } \\
\text { technology use } \\
\text { and social } \\
\text { connectedness }\end{array}$} & \multirow[t]{2}{*}{ School } & \multirow[t]{2}{*}{2 studies } & $\begin{array}{l}2 \text { out of } 2 \text { found school connectedness improved } \\
\text { (positive) }\end{array}$ & \multirow[t]{2}{*}{$\begin{array}{l}\text { Gross et al. (2002); Raghavendra et al. } \\
\text { (2012) }\end{array}$} \\
\hline & & & No negative association found & \\
\hline & \multirow[t]{2}{*}{ Friends/peers } & \multirow[t]{2}{*}{5 studies } & $\begin{array}{l}4 \text { out of } 5 \text { found technology promoted } \\
\text { connectedness among peers (positive) }\end{array}$ & $\begin{array}{l}\text { Donchi and Moore (2004); Gross et al. } \\
\text { (2002); Lim et al. (2013); } \\
\text { Raghavendra et al. (2012) }\end{array}$ \\
\hline & & & $\begin{array}{l}1 \text { out of } 5 \text { found technology led to poor peers } \\
\text { relationships (negative) }\end{array}$ & Punamäkia et al. (2009) \\
\hline & \multirow[t]{2}{*}{ Family } & \multirow[t]{2}{*}{3 studies } & No positive association found & \\
\hline & & & $\begin{array}{l}1 \text { out of } 3 \text { : found technology led to weak parents } \\
\text { relationships (negative) } 2 \text { out of } 3 \text { : no associations } \\
\text { found between technology use and connectedness } \\
\text { to family (negative) }\end{array}$ & $\begin{array}{l}\text { Holtz and Appel (2011); Punamäkia } \\
\text { et al. (2009); Raghavendra et al. } \\
\text { (2012) }\end{array}$ \\
\hline \multirow{6}{*}{$\begin{array}{l}\text { Internet } \\
\text { technology use } \\
\text { and mental } \\
\text { health }\end{array}$} & \multirow[t]{2}{*}{ Depression } & \multirow[t]{2}{*}{5 studies } & $\begin{array}{l}1 \text { out of } 5 \text { : found technology led to feeling of } \\
\text { depression (positive) }\end{array}$ & Park et al. (2012) \\
\hline & & & $\begin{array}{l}4 \text { out of } 5 \text { : no associations found between } \\
\text { technology use and feeling of depression } \\
\text { (negative) }\end{array}$ & $\begin{array}{l}\text { Banjanin et al. (2015); Dempsey et al. } \\
\text { (2009); Frison and Eggermont } \\
\text { (2015); Holtz and Appel (2011) }\end{array}$ \\
\hline & \multirow[t]{2}{*}{ Anxiety } & \multirow[t]{2}{*}{3 studies } & $\begin{array}{l}2 \text { out of } 3 \text { : found technology promoted the feeling of } \\
\text { anxiety (positive) }\end{array}$ & $\begin{array}{l}\text { Delonga et al. (2011); Gross et al. } \\
\text { (2002) }\end{array}$ \\
\hline & & & $\begin{array}{l}1 \text { out of } 3 \text { : no associations found between } \\
\text { technology use and feeling of anxiety }\end{array}$ & Holtz and Appel (2011) \\
\hline & \multirow[t]{2}{*}{ Loneliness } & \multirow[t]{2}{*}{6 studies } & $\begin{array}{l}5 \text { out of } 6: \text { found technology led to the feeling of } \\
\text { loneliness (positive) }\end{array}$ & $\begin{array}{l}\text { Delonga et al. (2011); Donchi and } \\
\text { Moore (2004); Gross et al. (2002); } \\
\text { Huang and Yang (2013); Punamäkia } \\
\text { et al. (2009) }\end{array}$ \\
\hline & & & 1 out of $6:$ no negative association found & Holtz and Appel (2011) \\
\hline
\end{tabular}

revealed that adolescents participate in virtual playgrounds in part to experience positive reinforcement of social connection. Recall that the concept of cyberspace was used to describe a space for adolescents to interact and connect by using social networks. In a previous study, it has been reported that $84 \%$ of adolescent use Instant Message (IM) either by cell phone or personal computer to communicate with their friends (Gross et al. 2002). The convenience of IM provided an accessible pathway for adolescents to maintain connections, both with school acquaintances and with peers (i.e., personal friends). The advantages of the usage of Internet technology in promoting adolescents' sense of connection is not only a way to significantly increase the accessibility of networks of friends, but it is also an accepted medium by adolescents for them to maintain and manage their relationships with peers and friends (Dempsey et al. 2009; Gross et al. 2002; Holtz and Appel 2011; Huang and Yang 2013). The digital generation has extended their space for socialization from physical surroundings to a digital landscape and recognized cyberspace as a pervasive domain for their socialization process.

On the other hand, the negative impacts from relationships in the physical world were also difficult to reverse, or compensate for, through the use of Internet technology (Lim et al. 2013). This is true in spite of the positive relationships between Internet technology use and adolescent friend and school connectedness that were found in this review, and which are consistent with previous studies (Grieve et al. 2013; Irvine 2009; Pierce 2009). Adolescents find it difficult to distance themselves, for example, from bullying or otherwise delinquent peers, in part because it is easy to transfer, or project, their real-life social network into cyberspace. The virtues of convenient accessibility to friends brought by Internet technology are thus both a positive and a negative element. This is consistent with previous studies that reveal the potential positive impacts of technology use among adolescents which should be recognized and cultivated even though the challenge exists for young people to avoid negative influences while using technology (Austin et al. 2006; Livingstone 2008). In addition, adolescents did not use Internet technology to communicate with their family members while they did take advantage of Internet technology to seek connections with school and friends (Holtz and Appel 2011; Raghavendra et al. 2012). The negative effects of distancing adolescents from family with adolescents' Internet 
technology use at home is another issue that needs to be addressed (Punamäkia et al. 2009). Whether the use of Internet technology promotes adolescents' sense of connectedness to certain domains, adolescents need additional relationship management skills, as well as knowledge of technology, to maintain positive relationships with their social environment in day-to-day life and to protect their personal privacy and safety in the digital landscape.

Internet technology use can be viewed as an additional opportunity for adolescents to develop their self-identification and social skills when the technology is utilized effectively with purposeful design. The three studies focused on adolescents with physical disabilities or bisexual identity found basis for viewing Internet technology use as a source of psychological support (Delonga et al. 2011; Lim et al. 2013; Raghavendra et al. 2012). However, Internet surfing was found to give adolescents excuses to escape from their real-life social environment (Punamäkia et al. 2009) and can lead to more problematic behaviors such as online gaming addiction and compulsive Internet use. Adolescents who overemphasize connecting online with friends are often unable to handle real-life relationships, and have feelings of loneliness (Delonga et al. 2011; Donchi and Moore 2004; Huang and Yang 2013). Teenagers who have internal feelings of loneliness work especially hard at creating appealing online profiles. Their effort may be to achieve success in cyberspace given that they are not experiencing success in this area in offline settings. The differences between one's self-image in real, face-to-face life and one's self-image in cyberspace can create dissonance, and result in feelings of loneliness when they interact with the social environment. Thus, the strength of self-identity developed from their social environment becomes critical for adolescents to avoid mental health problems that can result from the use of Internet technologies.

Researchers found that online connections were often an extension of offline connections (Gross et al. 2002; Lim et al. 2013; Raghavendra et al. 2012). A stronger sense of online connectedness was linked to having friends or acquaintances known through school, sporting clubs or family. An adolescent's real life social network critically conditions the relationship between Internet technology use and adolescents' level of social connectedness, and can influence that relationship in a positive way. The essential elements based on real life are necessary to obtain their expected outcomes. An adolescent's real life [as opposed to virtual] social network is critically important for determining to what extent cyber-relationships will develop in a positive way. Again, the research reviewed here reveals both positive and negative aspects of Internet technology use among adolescents. The potential advantages of Internet technology use among adolescents also depend on two other aspects of this use: whom they interact with and what they are doing. Though Internet technology might provide additional opportunities for adolescents to seek connection, social networks and skills based on real life [as opposed to virtual] are still a necessary foundation for them to use technology in a beneficial way.

Instead of ignoring or pre-emptively sanctioning an adolescent's felt needs for Internet technology use, adults should develop proactive strategies to assist adolescents in exploring the virtual landscape. The focus needs to be on cultivating the positive, rather than seeking to preclude the negative. This may be complicated by the fact that Internet use contributes to an adolescent's social connectedness with friends, but not with family. In some respects, youth who engage in social behavior on the Internet require coaching similar to coaching received in sports. Before adolescents successfully "play" in the virtual digital landscape, they need basic skills acquired through practice. Youth programs originating in the local community or schools are natural sources of distinct real-life social networks for adolescents, and could be the basis for extending relationships into cyberspace. Adolescents can be expected to spontaneously take advantage of the Internet to stay connected with these distinct social groups. For adolescents in the digital generation, youth need to include cyberspace relationship management skills, as well as technology knowledge, in program design. Youth programs already provide positive contexts to guide adolescents in developing self-identity and social skills. The attributes of Internet technology can allow the positive impacts from youth programs for adolescents to be enhanced and perhaps enable a prolonged influence on an adolescent's connectedness maintenance.

There are some reasons to believe that views of the impacts of Internet technology on adolescents are changing from negative foci (e.g., cyberbullying) to potential positive developments (e.g., better formation of self-identify). The "black box" element in Internet technology use - the fact that we can see inputs and outputs, but not processes - cannot be expected to keep adolescents from using Internet technology. Researchers believe that well-designed activities in the digital landscape can be key factors in encouraging adolescents to construct developmental assets that lead to positive outcomes (Bers 2012). The potential benefits and challenges in using virtual playgrounds to promote adolescents' sense of connectedness and contribute positively to their mental health need further research, exploration and discussion. The findings from this systematic review provide a basis for further discussion and inquiry regarding both the positive and negative dimensions of Internet technology use, and the role of adults, parents, practitioners, and researchers, in guiding and providing frames of reference for an adolescent's Internet technology use. 
The current study has limitations. First, this study resulted from the selection of only articles that have been published in academic journals. In doing so, other findings regarding the relationship between Internet technology use and mental health indicators may have been missed if reported in other places such as magazines, program reports, or community reports. Second, there is also the likelihood that articles were missed due to the constraints of the search. As noted earlier, the breadth of formulation of the searches had a distinct effect on the number of articles retrieved. Because there is no consensus on what defines an adolescent, studies whose populations might reasonably be considered adolescents may not have been included.

\section{Conclusion}

This study is unique given its focus on the positive side of Internet technology use in promoting adolescents mental health (i.e., sense of connectedness), instead of problematic behaviors (e.g., Internet addiction). Despite its limitations, this review reports the findings that the use of Internet technology leads to an increased sense of connectedness to friend and school, while at the same time increasing levels of anxiety and loneliness among adolescents. The potential positive impacts of technology use among adolescents should be recognized, cultivated, further examined, and developed to provide young people additional support in the digital landscape.

Findings from this study hold important implications for both research and practice by proposing the essential elements to reinforce adolescents' sense of connectedness for positive cyber-relationships. Only a relatively small amount of research has discussed how adolescents' social skills based on real life are critically important for their expected outcome in the digital playground. The positive cyber-relationship is also highly related to how adolescents extend their social network from real life to cyberspace. Future research and practice should give specific attention to and promote programming interventions that are designed to support adolescents' construction of social skills in real life, and then further consider the inclusion of Internet technology use to assist in their socialization processes.

This study suggests that adults who interact with youth should consider the development of a digital landscape and incorporate Internet technology to promote adolescents' social connectedness. Adolescents' sense of connectedness to friends and school are increased with the use of Internet technology with positive relationship support from their real life. The findings underscore that adolescents are potentially utilizing Internet technology for their sense of connectedness.
Acknowledgments The authors are pleased to acknowledge the support of the Youth Development program and the Department of Recreation, Park and Tourism Sciences at Texas A\&M University.

Authors' Contributions $Y W$ conceived of the study, participated in its design and data collection coordination, conducted measurement and statistical analysis, interpretation of the data, and drafted manuscript; $C O$ conceived of the study, participated in its design, coordination and analysis, assisted with interpretation of data and manuscript draft; $D M$ participated in the data interpretation and manuscript revision; TM participated in the data interpretation and manuscript revision. All authors read and approved the final manuscript.

\section{Compliance with Ethical Standards}

Conflicts of interest The authors report no conflict of interests.

\section{References}

Austin, E. W., Chen, Y., Pinkleton, B. E., \& Johnson, J. Q. (2006). Benefits and costs of channel one in a middle school setting and the role of media-literacy training. Pediatrics, 117(3), 423-433.

Banjanin, N., Banjanin, N., Dimitrijevic, I., \& Pantic, I. (2015). Relationship between internet use and depression: Focus on physiological mood oscillations, social networking and online addictive behavior. Computers in Human Behavior, 43, 308-312.

Barber, B. K., \& Schluterman, J. M. (2008). Connectedness in the lives of children and adolescents: A call for greater conceptual clarity. Journal of Adolescent Health, 43, 209-216.

Beam, M. R., Chen, C., \& Greenberger, E. (2002). The nature of adolescents' relationships with their "very important" nonparental adults. American Journal of Community Psychology, $30(2), 305-325$.

Bers, M. U. (2012). Designing digital experiences for positive youth development from playpen to playground (1st ed.). MA: Oxford University Press.

Boyd, D. (2008). In D. Buckingham (Ed.), Why youth heart social network sites: The role of networked publics in teenage social life. MA: MIT Press.

Delonga, K., Torres, H. L., Kamen, C., Evans, S. N., Lee, S., Koopman, C., \& Gore-Felton, C. (2011). Loneliness, internalized homophobia, and compulsive internet use: Factors associated with sexual risk behavior among a sample of adolescent males seeking services at a community LGBT center. Sexual Addiction \& Compulsivity, 18, 61-74.

Dempsey, A. G., Sulkowski, M. L., Nichols, R., \& Storch, E. A. (2009). Differences between peer victimization in cyber and physical settings and associated psychosocial adjustment in early adolescence. Psychology in the Schools, 46(10), 962-972.

Donchi, L., \& Moore, S. (2004). It's a boy thing: The role of the Internet in young people's psychological wellbeing. Behaviour Change, 21(2), 76-89.

DuBois, D. L., \& Silverthorn, N. (2005). Natural mentoring relationships and adolescent health: Evidence from a national study. American Journal of Public Health, 95(3), 518-524.

Frison, E., \& Eggermont, S. (2015). The impact of daily stress on adolescents' depressed mood: The role of social support seeking through Facebook. Computers in Human Behavior, 44, 315-325.

Grieve, R., Indian, M., Witteveen, K., Tolan, G. A., \& Marrington, J. (2013). Face-to-face or Facebook: Can social connectedness be derived online? Computers in Human Behavior, 29(3), 604-609.

Gross, E. F., Juvonen, J., \& Gable, S. L. (2002). Internet use and wellbeing in adolescence. Journal of Social Issues, 58(1), 75. 
Hawkins, J. D., Catalano, R. F., Kosterman, R., Abbott, R. D., \& Hill, K. G. (1999). Preventing adolescent health-risk behaviors by strengthening protection during childhood. Archives of Pediatrics and Adolescent Medicine, 153(3), 226-234.

Holtz, P., \& Appel, M. (2011). Internet use and video gaming predict problem behavior in early adolescence. Journal of Adolescence, 34(1), 49-58.

Huang, C. L., \& Yang, S. C. (2013). A study of online misrepresentation, self-disclosure, cyber-relationship motives, and loneliness among teenagers in Taiwan. Journal of Educational Computing Research, 48(1), 1-18.

Irvine, C. (2009). Excessive chatting on Facebook can lead to depression in teenage. Resource document. The Daily Telegraph. http://www.telegraph.co.uk/technology/facebook/4405741/ Excessive-chatting-on-Facebook-can-lead-to-depression-in-teen age-girls.html.

Karcher, M. J. (2011). The hemingway: Measure of adolescent connectedness. Unpublished manuscript. Retrieved from http:// adolescentconnectedness.com/.

Liberati, A., Altman, D. G., Tetzlaff, J., Mulrow, C., \& Gøtzsche, P. C. (2009). The PRISMA statement for reporting systematic reviews and meta-analyses of studies that evaluate health care interventions: Explanation and elaboration. PLOS Medicine, 6(7), e1000100.

Lim, S. S., Chan, Y. H., Vadrevu, S., \& Basnyat, I. (2013). Managing peer relationships online-Investigating the use of Facebook by juvenile delinquents and youths-at-risk. Computers in Human Behavior, 29, 8-15.

Livingstone, S. (2008). Taking risky opportunities in youthful content creation: Teenagers' use of social networking sites for intimacy, privacy and self-expression. New Media \& Society, 10(3), 393-411.

Madden, M., Lenhart, A., Duggan, M., Cortesi, S. \& Gasser, U. (2013). Teens and technology 2013. Resource document. Pew Research Center. http://www.pewinternet.org/Reports/2013/ Teens-and-Tech.aspx.

Mistler-Jackson, M., \& Songer, N. B. (2000). Student motivation and Internet technology: Are students empowered to learn science? Journal of Research Science Teach, 37, 459-479.

Olsson, C. A., McGee, R., Nada-Raja, S., \& Williams, S. M. (2013). 32-year longitudinal study of child and adolescent pathways to well-being in adulthood. Journal of Happiness Studies, 14(3), 1069-1083.

Park, S., Hong, K. M., Park, E. J., \& Yoo, H. J. (2012). The association between problematic internet use and depression, suicidal ideation and bipolar disorder symptoms in Korean adolescents. Australian and New Zealand Journal of Psychiatry, 47(2), 153-159.

Pew Research. (2013-03-13). Teens and technology 2013. Resource document. Pew Research Center. http://www.pewinternet.org/ 2013/03/13/teens-and-technology-2013/.

Pierce, T. (2009). Social anxiety and technology: Face-to-face communication versus technological communication among teens. Computers in Human Behavior, 25(6), 1367-1372.

Punamäkia, R., Walleniusa, M., Hölttöa, H., Nygårdc, C., \& Rimpeläc, A. (2009). The associations between information and communication technology (ICT) and peer and parent relations in early adolescence. International Journal of Behavioral Development, 33(6), 556-564.

Raghavendra, P., Wood, D., Newmanc, L., \& Lawryd, J. (2012). Why aren't you on Facebook?: Patterns and experiences of using the internet among young people with physical disabilities. Technology and Disability, 24, 149-162.

Stoddard, S. A., McMorris, B., \& Sieving, R. E. (2011). Do social contexts and hope matter in predicting early adolescent violence? American Journal of Community Psychology, 48, 247-256.

Sum, S., Mathews, M. R., Pourghasem, M., \& Hughes, I. (2008). Internet technology and social capital: How the internet affects seniors' social capital and wellbeing. International Communication Association, 14, 202-220.

Uchino, B. N., Cacioppo, J. T., \& Kiecolt-Glaser, J. K. (1996). The relationship between social support and psychological processes: A review with emphasis on underlying mechanisms and implications for health. Psychological Bulletin, 119, 488-531.

Walton, G. M., \& Cohen, G. L. (2011). A brief social-belonging intervention improves academic and health outcomes of minority students. Science, 331, 1447-1451.

Zimmerman, M. A., Bingenheimer, J. B., \& Notaro, P. C. (2002). Natural mentors and adolescent resiliency: A study with urban youth. American Journal of Community Psychology, 30(2), 221-243. 